\title{
Genetic structure of the American ginseng (Panax quinquefolius L.) in Eastern Canada using reduced- representation high-throughput sequencing
}

\begin{tabular}{|r|l|}
\hline Journal: & Botany \\
\hline Manuscript ID & cjb-2016-0144.R2 \\
\hline Manuscript Type: & Note \\
\hline Complete List of Authors: & $\begin{array}{l}\text { Joly, Simon; Jardin botanique de Montreal, } \\
\text { Archambault, Annie; Quebec Centre for Biodiversity Science } \\
\text { Pellerin, Stéphanie; Institut de recherche en biologie vegetale, Universite } \\
\text { de Montreal/Jardin botanique de Montreal } \\
\text { Nault, Andrée; Espace pour la Vie }\end{array}$ \\
\hline Keyword: & $\begin{array}{l}\text { medicinal herb, genetic diversity, Next-generation sequencing (NGS), } \\
\text { genetic structure, conservation }\end{array}$ \\
\hline &
\end{tabular}

SCHOLARONE ${ }^{\mathrm{m}}$

Manuscripts 


\section{Genetic structure of the American ginseng (Panax quinquefolius L.) in Eastern Canada using reduced-representation high-throughput sequencing}

Simon Jolya,b,*, Annie Archambault ${ }^{c}$, Stéphanie Pellerin ${ }^{\mathrm{a}, \mathrm{b}}$, Andrée Nault ${ }^{\mathrm{d}}$

a Institut de recherche en biologie végétale, 4101 Sherbrooke Est, Montréal, QC, H1X 2B2, Canada

b Jardin botanique de Montréal, 4101 Sherbrooke Est, Montréal, QC, H1X 2B2, Canada

c Québec Centre for Biodiversity Science, 1205 Dr Penfield, Montréal, QC, H3A 1B1, Canada

d Biodôme de Montréal, 4777 Avenue Pierre-de Coubertin, Montréal, QC, H1V 1B3, Canada

* Author for correspondence: joly.simon@gmail.com; phone: +1 514-872-0344. 


\section{Abstract}

The American ginseng (Panax quinquefolius L.) has been used for a wide range of medicinal purposes for more than 300 years and is at risk in most of its range due to harvesting in natural populations, herbivory, and habitat loss. Its genetic structure is largely unknown in the previously glaciated areas of Eastern Canada although such information could provide useful information for restoration strategies. We generated and analysed data from a reduced-representation high-throughput sequencing approach with a BAMOVA population model to partition the genetic variation within and among six natural populations of American ginseng in Eastern Canada. We found that an important and significant fraction of the genetic variation was structured among populations $\left(\phi_{S T}=42 \% ; F_{S T}=34 \%\right)$ at the geographical scale of the study $(<250 \mathrm{~km})$. No clear evidence of isolation-by-distance was observed. This important genetic structure observed among American ginseng populations from a region that was covered by ice during the last glaciations is similar to what had been found in previous studies on southern populations or throughout the species range.

Keywords: Next-generation sequencing (NGS); genetic structure; medicinal herb; conservation; genetic diversity. 


\section{Résumé}

Le ginseng à cinq folioles (Panax quinquefolius L.) est utilisé comme plante médicinale depuis plus de 300 ans et est vulnérable dans l'ensemble de son territoire dû à la récolte des racines, au broutage et à la perte d'habitat. La structure génétique du ginseng est peu connue dans les régions affectées par les dernières glaciations de l'est du Canada, bien qu'une telle information puisse aider à développer des stratégies de conservation. Dans cette étude, nous avons généré et analysé des données de séquençage à haut débit d'une fraction réduite de son génome à l'aide d'une approche BAMOVA par population afin de partitionner la variation génétique en fractions intra- et inter-populations. Nous avons observé qu'une fraction importante et significative de la variation était structurée entre les populations $\left(\phi_{S T}=42 \% ; F_{S T}=34 \%\right)$ à l'échelle de l'étude $(<250 \mathrm{~km})$. Aucune évidence de patron d'isolation par distance n'a été observée. Cette structure importante observée entre les populations du ginseng à cinq folioles situées dans la partie de l'aire de répartition recouverte de glace lors des dernières glaciations est similaire à ce qui a été observée dans des études antérieures effectuées dans le sud ou dans l'ensemble de l'aire de répartition de l'espèce.

Keywords: Séquençage nouvelle génération; structure génétique; plante médicinale; conservation; diversité génétique. 


\section{Introduction}

American ginseng (Panax quinquefolius L.; Araliaceae) is a long-lived understorey herb of the eastern deciduous forest of North America. It has been harvested for its fleshy root used for a wide range of medicinal purposes for more than 300 years (Robbins 1998, McGraw et al. 2013), while concerns due to the harvesting in wild populations were raised as early as 1770 (Kalm 1987). This non-clonal species is indeed highly sensitive to harvest; collecting roots of about $5 \%$ of productive plants (i.e., with at least three leaves) every year is enough to induce population decline (Nantel et al. 1996). Similarly, harvesting also impacts genetic diversity and structure (Cruse-Sanders and Hamrick 2004). Despite the fact that the American ginseng is listed in the Convention on International Trade in Endangered Species of Wild Fauna and Flora (CITES), legally protected in Canada (Species at Risk Act (SARA); Environment Canada 2015) and in the USA (McGraw et al. 2013), it is still threatened by legal and illicit harvesting as well as herbivory and habitat loss (McGraw and Furedi 2005, Souther and McGraw 2014).

To preserve wild populations of American ginseng, restoration efforts have been going on for the last 20 years in Canada (Environment Canada 2015). Because of the potential impact restoration or reintroduction programs can have on natural populations (IUCN 1987, Broadhurst et al. 2008), such efforts in the province of Québec were always performed using seeds from the target or the nearest viable population (A. Nault, unpublished data). This was done to minimise the risk of losing locally adapted genetic diversity and minimize outbreeding depression (Broadhurst et al. 2008), especially given that populations targeted for restoration typically have small sizes as they are the ones suspected to lack sustainability. Yet, this assumes genetic structure among populations, at least for certain regions of the genome, but virtually nothing is known of local population structure of this tetraploid species in Eastern Canada. The few studies that investigated genetic variation in natural populations of American ginseng have generally found strong population structure, but these were either performed over large geographical areas (Boehm et al. 1999, Grubbs and Case 2004, Cruse-Sanders and Hamrick 2004) or on populations from the centre of the species' distribution (West Virginia; Obae and West 2011). These results can hardly be extrapolated to populations from previously glaciated 
areas, which are known to have distinct diversity patterns due to their demographic histories (Hewitt 2000, Davis and Shaw 2001). Two studies assessed the genetic diversity of American ginseng in the previously glaciated portion of its range using random amplified polymorphic DNA (RAPD). One studied nine populations from New York State (Lim et al. 2007) and the other three from the Quebec province (Schluter and Punja 2002). Although both found considerable within population variation, neither found compelling evidence of population structure nor quantified the amount of variation partitioned among populations.

We present the results of a pilot study where the objective was to quantify the genetic population structure at a local scale among American ginseng populations in Eastern Canada. The project, initiated in 2010, aimed at testing a high-throughput reducedrepresentation sequencing approach at the population level (DNA pooling) on a non-model polyploid organism. The results demonstrate that an important and significant amount of genetic variation is partitioned among populations of the American ginseng in Eastern Canada.

\section{Methods}

\section{Plant material}

Five sustainable American ginseng populations were sampled from Southern Quebec and one from Eastern Ontario (Fig. 1); the most distant populations were $250 \mathrm{~km}$ apart (Table S1). Populations were selected among those that were less likely to have been affected by human populations, either by harvesting or reintroductions (Désilets et al. 2011). Their precise locations cannot be published for protection purposes, but county information and governmental record numbers are given in Table 1 and geographic distances in Table S1. For each population, leaf material was sampled from ten large distant individuals in order to cover all occupied area. Leaves were immediately dried in silica gel for molecular work.

\section{Molecular work, sequencing, and bioinformatics}

Detailed methods used for the molecular work, sequencing and bioinformatics analyses are available as supplementary material. Briefly, we used a complexity reduction of 
polymorphic sequences (CRoPS) strategy (Davey et al. 2011) for investigating genetic variation in populations. Total DNA was digested with restriction enzymes and adaptors were ligated to the fragments. Selective primers then amplified a fraction of the fragments and the pool of amplified fragments was sequenced on one quarter of a Roche 454 run (Genome Québec Innovation Centre, Montréal, Canada). We followed Gompert et al. (2010) in using a population level approach in which all individuals from a population were marked with the same common barcode, quantified, and pooled together in equal amount of DNA prior to sequencing. Although individual genotype information is lost with this approach, population allele frequencies and population structure can be estimated (Gompert et al. 2010). Moreover, de Vriendt et al. (2016) have shown that allelic frequencies obtained with population level DNA pooling were highly similar to that obtained with an individual-based genotyping approach.

Sequences were filtered for adaptors and poor quality nucleotides prior to de novo contig assembly in Geneious (Drummond et al. 2014) with the following parameters: min. overlap: $30 \mathrm{bp}$, min. overlap identity: 97\%, word length: 10, max. ambiguity: 16, reanalyse threshold: 2, gaps max. size: 3 . To test whether the assembly algorithm affects the results, contigs were also assembled in SeqMan NGen (DNAStar Inc., Madison, WI; see suppl. mat. for parameters) and gave the same results (data not shown). To eliminate biases in subsequent analyses, we used a BLAST approach to identify and discard contigs of chloroplast, mitochondrial, ribosomal, or bacterial origin, as well as putative transposon sequences. We also discarded over-represented contigs that could represent putative duplicated genes or large gene families. Finally, we removed contig regions with low sequence coverage and used a Coalescent theory approach (using evidence for intra-specific and inter-specific divergence times among sequences in a contig; see Suppl. Mat.) to remove contigs containing gene paralogs. This last step is important because the American ginseng is an ancient tetraploid (Lee and Wen 2004). Finally, only contigs represented by at least two sequences in each population were retained.

\section{Population genomics}


Population structure was estimated with the Bayesian approach of Gompert et al. (2010) implemented in BAMOVA (Gompert and Buerkle 2011). It uses a Bayesian hierarchical model to estimate locus specific and genome wide $\phi_{S T}$ (Excoffier et al. 1992), which is the amount of molecular variance partitioned among populations. Five independent chains of 500000 generations were run with the parameters "-l 1 -v 0.2 -D 1 -a 0 -w 2000 -c 0.8", which were found to give the best chain mixing. The chain was sampled every 100 generations and the first 200000 generations were discarded as burnin. Convergence and mixing of the chains was assessed visually and statistically using the coda package (Plummmer et al. 2006) in R (R core team 2015).

We also estimated $F_{S T}$ based on nucleotide polymorphisms as in Nordborg et al. (2005, see supplementary material for details). A global $F_{S T}$ value was estimated among all populations, as well pairwise $F_{S T}$ values between all pairs of populations. These latter values were used to reconstruct a population network using the NeighborNet algorithm (Bryant and Moulton 2004) in SplitsTree4 (Huson and Bryant 2006). $F_{S T}$ statistics and networks were also estimated on the chloroplast and mitochondrial markers that were set-aside during the filtering steps.

We finally tested for a pattern of isolation-by-distance in the data using a distance-based redundancy analysis (dbRDA; Legendre and Anderson 1999). The response matrix consisted of the vector coordinates of a principal coordinate analysis of the $F_{S T}$ matrix and the predictors were the latitude and longitude of populations. The significance of the models was tested by ANOVA and adjusted $R^{2}$ were reported. Analyses were performed with the R package vegan (Oksanen et al. 2012).

\section{Results}

A total of 248740 reads were obtained, ranging from 34836 to 51899 (mean = 41457 ) per population (raw data was deposited on NCBI SRA archive [SRR4436938SRR4436943] and processed data was deposited on Figshare [doi: 10.6084/m9.figshare.3412990]). The raw sequence lengths varied from 0 to $648 \mathrm{bp}$ 
(median [N50] = 71). A total of 134509 reads, out of 248740 , were assembled to produce 13235 contigs, varying in length between 30 and 813 bp (median [N50]: 214, mean: 145).

In total, 153 contigs were identified to be of chloroplast or mitochondrion origin, 120 contained ribosomal sequences, and 91 were potentially identified as transposons. No sequences were found to be of bacterial or fungal origin, but 435 contigs were identified as representing gene families or containing paralogs. Ultimately, 751 contigs passed all filtering criteria and 46 had coverage of at least two in each population and were used in the subsequent population genomics analyses. Similarly, 79 chloroplast and 11 mitochondrial contigs were included in further analyses.

The five BAMOVA runs converged for all variables. The potential scale reduction factor (PSRF) was below 1.03 for all variables and was 1 for $\phi_{S T}$, the variable of interest. Effective sample sizes (corrected for chain autocorrelation) were above 1000 for all parameters. The posterior distribution of $\phi_{S T}$ shows that genetic variation is strongly partitioned between populations, with $41.9 \%$ of the variation being explained among populations (95\% confidence interval: $33.8 \%-49.3 \%$ ). The global $F_{S T}$ estimate was 0.34 , which supported the BAMOVA results in suggesting an important differentiation among populations. The pairwise population $F_{S T}$ were all between 0.12 and 0.15 and the population network shows an absence of structure (Fig. 2A). There was no evidence of an isolation-by-distance pattern $\left(R_{a d j}{ }^{2}=0.028\right.$; ANOVA $F$ stat. $\left.p=0.30\right)$, although this result should be taken with caution due to the small number of populations included.

The global population structure obtained for chloroplast and mitochondrial markers were about half that of the nuclear markers (chloroplast $F_{S T}=0.18$; mitochondrial $F_{S T}=$ 0.17). A lower value is expected because the mutation rates of the organellar genomes are lower than for the nuclear genome in plants. However, because the exact mutation rates are unknown for ginseng, a direct comparison of population structure is not possible between the genomes. There was no evidence of isolation-by-distance for the chloroplast data $\left(\operatorname{Radj}^{2}\right.$ $=-0.066$, ANOVA $F$ stat. $p=0.58$ ), whereas a marginally significant isolation-by-distance signal was found with the mitochondrial data $\left(R_{a d j}{ }^{2}=0.66\right.$, ANOVA $F$ stat. $\left.p=0.031\right)$. The population networks estimated from pairwise population organellar $F_{S T}$ values illustrate these results. The network of the chloroplast data showed that two populations (CDPNQ 
3677 and CDPNQ 3690) were slightly more distant from the others (Fig. 2B), but they were not particularly close geographically to each other (Fig. 2D). In contrast, the mitochondrial population network illustrated why an isolation-by-distance was detected, as the two most distant populations at the genetic level (ON and CDPNQ 18468) were also the most geographically distant populations (Fig. 2C and 2D).

\section{Discussion}

We found that a strong and significant amount of the genetic variation is partitioned among studied populations of the American ginseng in Eastern Canada, both in terms of $\phi_{S T}$ (42\%) and $F_{S T}(34 \%$; nuclear genome). However, we did not observe a clear genetic structure among the populations studied, perhaps because of their small geographic extent. The genetic variation explained among populations is similar to what has been found across a slightly greater region in West Virginia with RAPD markers (47.3\%; Obae and West 2011) and concurs with studies that investigated population structure across the species' range (Grubbs and Case 2004, Cruse-Sanders and Hamrick 2004). Notably, it is the first time that a strong and significant population structure is estimated among populations found in the previously glaciated portion its range. Indeed, previous studies in this region using polymorphic RAPD markers did not show clear evidence of genetic structure among populations or did not quantify the proportion of genetic variation partitioned among populations (Schluter and Punja 2002, Lim et al. 2007). These results are important as recent population expansions such as the one that occurred in American ginseng following glacier retreats at the end of the Pleistocenehave important population genetic consequences that prevent the extrapolation of results from previous studies to previously glaciated regions. These peculiar genetic conditions are caused, firstly, by the spread of rare mutations on the migration front that increase genetic differentiation (Edmonds et al. 2004) and, secondly, by lowering effective population size and therefore reducing genetic diversity (Hewitt 2000).

The significant population structure observed here provides relevant information for the management of the American ginseng in Eastern Canada. First, this population structure at this geographical scale might be seen as supporting actual restoration strategies that use 
seeds from neighbouring populations in restoration project. The idea behind this is to minimize the impact on local genotypes given the small population sizes, maximise local adaptation and minimize outbreeding depression (Broadhurst et al. 2008). Whether this strategy is the best one, however, is debatable (Jones 2013) and should be investigated further for the American ginseng. Indeed, a large proportion of the markers supporting this structure might be neutral and thus may not indicate locally adapted genotypes. The absence of isolation-by-distance patterns in the data might be interpreted as an indirect evidence of local adaptation, but this is highly speculative because of the small number of populations involved and of the highly fragmented nature of the landscape between these populations. However, even in the presence of locally adapted genotypes, favouring limited gene flow among populations may help spread useful mutations or reduce inbreeding depression and consequently increase mean population fitness (Broadhurst et al. 2008). Future studies are needed to decide on the most appropriate strategies for preserving this species.

Besides harvesting, threats to local diversity can also come from ginseng cultivation in natural ecosystems, a practice recently gaining popularity (Nadeau and Olivier 2003). Indeed, forest farming practices could threaten the native variation (Environment Canada 2015) if little care is given to seed provenance (no regulation currently exist about this issue in Canada and in the United States of America) and if cultivated areas are established near wild populations. Close proximity of natural and cultivated populations could result in introgression of foreign genes into the indigenous genetic background and contribute to the loss of local diversity if this process is important (McGraw et al. 2013).

While our results were statistically supported, we acknowledge that the sample sizes used in this pilot investigation were sub-optimal even if they are similar to previous studies that used a DNA-pooling approach (e.g., Gompert et al. 2010 used 15 individuals per population). Nevertheless, the Bayesian BAMOVA approach accounts for the error involved in sampling individuals from populations (Gompert et al. 2010). As such, the confidence intervals obtained partly reflect this uncertainty and reinforces the strong signal of genetic structure in the data regardless of the limited sampling. 
Despite our efforts in selecting the size of fragments to be sequenced, many short contigs were obtained, which resulted in a decreased sequencing depth (number of reads per marker). Nevertheless, the number of markers we obtained was sufficient to assess the neutral genetic structure of American ginseng. Since the start of this project in 2010, other reduced representation sequencing approaches have gained in popularity, such as RADsequencing or Genotyping by Sequencing (Baird et al. 2008, Elshire et al. 2011), which allow individual genotyping for more loci and at lower cost than the technology used in this study. Sequencing depth should not affect our main conclusions as the BAMOVA approach accounts for the uncertainty in sampling sequences from individuals in DNA pools (Gompert et al. 2010). Nevertheless, the new techniques mentioned above appear more appropriate for subsequent investigations. In the future, the combination of such genomic approaches, combined with appropriate trait and fitness measures of plants, will allow designing better conservation strategies for the American ginseng.

\section{Acknowledgements}

We would like to acknowledge the help of Clément Robidoux, Marjorie Mercure, Mathieu Lemay, Renée Gagnon, David Maneli, and Shaun Thompson who collected the leafspecimens. We thank Sébastien Renaut for commenting on a previous version of the manuscript and the Genome Quebec Innovation Centre for advice and support. We also appreciated the intellectual support of Anne Bruneau and Daniel Schoen on this project. This work has been rendered possible do to the computing resources of Calcul Québec, to a seed grant from the Quebec Centre for Biodiversity Science (QCBS), financial support from the Laboratoires Klorane and Le jour de la Terre Québec, and an NSERC discovery grant to SJ.

\section{References}

Argus, G.W., and White, D.J. 1987. Panax quinquefolium L. In Atlas of the rare vascular plants of Ontario, Part 4. Edited by G.W. Argus, K.M. Pryer, D.J. White, and C.J. Keddy. National Museum of Natural Sciences, Ottawa, Canada. p. (looseleaf).

Baird, N.A., Etter, P.D., Atwood, T.S., Currey, M.C., Shiver, A.L., Lewis, Z.A., Selker, E.U., 
Cresko, W.A., and Johnson, E.A. 2008. Rapid SNP discovery and genetic mapping using sequenced RAD markers. PLoS ONE 3(10): e3376. doi:10.1371/journal.pone.0003376.

Boehm, C.L., Harrison, H.C., Jung, G., and Nienhuis, J. 1999. Organization of American and Asian Ginseng Germplasm Using Randomly Amplified Polymorphic DNA (RAPD) Markers. J. Am. Soc. Hortic. Sci. 124(3): 252-256.

Broadhurst, L.M., Lowe, A., Coates, D.J., Cunningham, S.A., McDonald, M., Vesk, P.A., and Yates, C. 2008. Seed supply for broadscale restoration: maximizing evolutionary potential. Evol. Appl. 1(4): 587-597. doi:10.1111/j.1752-4571.2008.00045.x.

Bryant, D., and Moulton, V. 2004. Neighbor-Net: an agglomerative method for the construction of phylogenetic networks. Mol. Biol. Evol. 21(2): 255-265.

Cruse-Sanders, J.M., and Hamrick, J.L. 2004. Genetic diversity in harvested and protected populations of wild American ginseng, Panax quinquefolius L. (Araliaceae). Am. J. Bot. 91(4): 540-548. doi:10.3732/ajb.91.4.540.

Davey, J.W., Hohenlohe, P.A., Etter, P.D., Boone, J.Q., Catchen, J.M., and Blaxter, M.L. 2011. Genome-wide genetic marker discovery and genotyping using next-generation sequencing. Nat. Rev. Genet. 12(7): 499-510. doi:10.1038/nrg3012.

Davis, M.B., and Shaw, R.G. 2001. Range Shifts and Adaptive Responses to Quaternary Climate Change. Science 292(5517): 673-679. doi:10.1126/science.292.5517.673.

Désilets, P., Jolicoeur, G., and Couillard, L. 2011. Plan de conservation du ginseng à cinq folioles (Panax quinquefolius), espèce menacée au Québec. Ministère du Développement durable, de l'Environnement et des Parcs, Direction du patrimoine écologique et des parcs, Gouvernement du Québec, Québec.

Drummond, A.J., Ashton, B., Buxton, S., Cheung, M., Cooper, A., Heled, J., Kearse, M., Moir, R., Stones-Havas, S., Sturrock, S., Thierer, T., and Wilson, A. 2014. Geneious. Biomatters, Auckland, New Zealand. Available from http://www.geneious.com.

Edmonds, C.A., Lillie, A.S., and Cavalli-Sforza, L.L. 2004. Mutations arising in the wave front of an expanding population. Proc. Natl. Acad. Sci. U. S. A. 101(4): 975-979.

doi:10.1073/pnas.0308064100.

Elshire, R.J., Glaubitz, J.C., Sun, Q., Poland, J.A., Kawamoto, K., Buckler, E.S., and Mitchell, S.E. 2011. A robust, simple genotyping-by-sequencing (GBS) approach for high diversity species. PLoS ONE 6(5): e19379. doi:10.1371/journal.pone.0019379.

Environment Canada. 2015. Recovery strategy for American ginseng (Panax quinquefolius) in Canada [proposed]. Species at Risk Act Recovery Strategies, Environment Canada, Ottawa, Canada.

Excoffier, L., Smouse, P., and Quattro, J. 1992. Analysis of molecular variance inferred from metric distances among DNA haplotypes: application to human mitochondrial DNA restriction data. Genetics 131: 479-491.

Gompert, Z., and Buerkle, C.A. 2011. A hierarchical Bayesian model for next-generation population genomics. Genetics 187(3): 903 -917. doi:10.1534/genetics.110.124693.

Gompert, Z., Forister, M.L., Fordyce, J.A., Nice, C.C., Williamson, R.J., and Buerkle, C.A. 2010. 
Bayesian analysis of molecular variance in pyrosequences quantifies population genetic structure across the genome of Lycaeides butterflies. Mol. Ecol. 19(12): 2455-2473. doi:10.1111/j.1365-294X.2010.04666.x.

Grubbs, H.J., and Case, M.A. 2004. Allozyme variation in American ginseng (Panax quinquefolius L.): Variation, breeding system, and implications for current conservation practice. Conserv. Genet. 5(1): 13-23. doi:10.1023/B:COGE.0000014064.44592.bc.

Hewitt, G. 2000. The genetic legacy of the Quaternary ice ages. Nature 405(6789): 907-913. doi:10.1038/35016000.

Huson, D.H., and Bryant, D. 2006. Application of phylogenetic networks in evolutionary studies. Mol. Biol. Evol. 23(2): 254-267.

IUCN. 1987. IUCN Position Statement on translocation of living organisms: introductions, re-introductions and re-stocking. 22nd meeting of the IUCN Council, Gland, Switzerland.

Jones, T.A. 2013. When local isn't best. Evol. Appl. 6(7): 1109-1118. doi:10.1111/eva.12090.

Kalm, P. 1987. Peter Kalm's travels in North America: the English version of 1770. Translated byA.B. Benson. Dover.

Lee, C., and Wen, J. 2004. Phylogeny of Panax using chloroplast trnC-trnD intergenic region and the utility of trnC-trnD in interspecific studies of plants. Mol. Phylogenet. Evol. 31(3): 894-903. doi:10.1016/j.ympev.2003.10.009.

Legendre, P., and Anderson, M.J. 1999. Distance-based redundancy analysis: testing multispecies responses in multifactorial ecological experiments. Ecol. Monogr. 69(1): 1-24. doi:10.2307/2657192.

Lim, W., Mudge, K., and Weston, L. 2007. Utilization of RAPD markers to assess genetic diversity of wild populations of North American ginseng (Panax quinquefolium). Planta Med. 73(1): 71-76. doi:10.1055/s-2006-951768.

McGraw, J.B., and Furedi, M.A. 2005. Deer Browsing and Population Viability of a Forest Understory Plant. Science 307(5711): 920-922. doi:10.1126/science.1107036.

McGraw, J.B., Lubbers, A.E., Van der Voort, M., Mooney, E.H., Furedi, M.A., Souther, S., Turner, J.B., and Chandler, J. 2013. Ecology and conservation of ginseng (Panax quinquefolius) in a changing world. Ann. N. Y. Acad. Sci. 1286(1): 62-91. doi:10.1111/nyas.12032.

Nadeau, I., and Olivier, A. 2003. Revue de la biologie et de la production du ginseng à cinq folioles (Panax quinquefolius L.) en milieu forestier au Canada. Can. J. Plant Sci. 83: 877-891. doi:10.4141/P02-092.

Nantel, P., Gagnon, D., and Nault, A. 1996. Population Viability Analysis of American Ginseng and Wild Leek Harvested in Stochastic Environments. Conserv. Biol. 10(2): 608-621. doi:10.1046/j.1523-1739.1996.10020608.x.

Nordborg, M., Hu, T.T., Ishino, Y., Jhaveri, J., Toomajian, C., Zheng, H., Bakker, E., Calabrese, P., Gladstone, J., Goyal, R., Jakobson, M., Kim, S., Morozov, Y., Padhukasahasram, B., Plagnol, V., Rosenberg, N.A., Shah, C., Wall, J.D., Wang, J., Zhao, K., Kalbfleisch, T., Schulz, V., Kreitman, M., and Bergelson, J. 2005. The pattern of polymorphism in Arabidopsis thaliana. PLoS Biol. 
3(7): e196. doi:10.1371/journal.pbio.0030196.

Obae, S.G., and West, T.P. 2011. Effects of anthropogenic activities on genetic diversity and population structure of American ginseng (Panax quinquefolius L.) growing in West Virginia. J. Hortic. For. 3(9): 270-281.

Oksanen, J., Blanchet, F.G., Kindt, R., Legendre, P., Minchin, P.R., O’Hara, R., Simpson, G.L., Solymos, P., Stevens, M.H.H., and Wagner, H. 2012. vegan: community ecology package. Available from http://CRAN.R-project.org/package=vegan.

Plummmer, M., Best, N., Cowles, K., and Vines, K. 2006. CODA: convergence diagnosis and output analysis for MCMC. R News 6(1): 7-11.

R core team. 2015. R: a language and environment for statistical computing. R Foundation for Statistical Computing, Vienna, Austria. Available from http://www.R-project.org.

Robbins, C.S. 1998. American ginseng: The root of North America's medicinal herb trade. Traffic North America, Washington, D.C., USA.

Schluter, C., and Punja, Z.K. 2002. Genetic diversity among natural and cultivated field populations and seed lots of American ginseng (Panax quinquefolius L.) in Canada. Int. J. Plant Sci. 163(3): 427-439. doi:10.1086/339512.

Souther, S., and McGraw, J.B. 2014. Synergistic effects of climate change and harvest on extinction risk of American ginseng. Ecol. Appl. 24(6): 1463-1477. doi:10.1890/13-0653.1. de Vriendt, L., Lemay, M.-A., Jean, M., Renaut, S., Pellerin, S., Joly, S., Belzile, F., and Poulin, M. 2016. Population isolation shapes plant genetics, phenotype and germination in naturally patchy ecosystems. J. Plant Ecol.: rtw071. doi:10.1093/jpe/rtw071.

Wessel, P., Smith, W.H.F., Scharroo, R., Luis, J., and Wobbe, F. 2013. Generic Mapping Tools: improved version released. Eos Trans. Am. Geophys. Union 94(45): 409-410.

doi:10.1002/2013E0450001. 


\section{Tables}

Table 1. Information on the populations sampled

\begin{tabular}{|ll|}
\hline Accession & Locality \\
\hline CDPNQ 3677 & MRC Le Haut-Richelieu, Québec \\
\hline CDPNQ 3690 & MRC Deux-Montagnes, Québec \\
\hline CDPNQ 3684 & MRC La Vallée-du-Richelieu, Québec \\
\hline CDPNQ 3715 & MRC Rouville, Québec \\
\hline CDPNQ 18468 & MRC Brome-Missisquoi, Québec \\
\hline ON $*$ & $\begin{array}{l}\text { Leeds and Grenville United Counties, } \\
\text { Ontario }\end{array}$ \\
\hline
\end{tabular}

Notes: CDPNQ: Centre de données sur le patrimoine naturel du Québec. * The Ontario population does not have a record from the Ontario Ministry of Natural Resources and Forestry; locality information is available upon request. 


\section{Figure Legends}

Fig. 1 American ginseng (Panax quinquefolius) distribution (modified from Argus and White 1987; (C) Canadian Museum of Nature) and study region from where the six populations were sampled. The map was generated using the Generic Mapping Tools software (Wessel et al. 2013).

Fig. 2 Networks representing the pairwise $F_{S T}$ distances between populations for $(A)$ the nuclear genome, (B) the chloroplast genome, and (C) the mitochondrial genome, as well as the pairwise geographic distances between populations (D). Boxes in the network indicate conflicting signal in the data. Bars indicate $F_{S T}$ distances $(A, B, C)$ or geographic distances in $\mathrm{km}(\mathrm{D})$. 


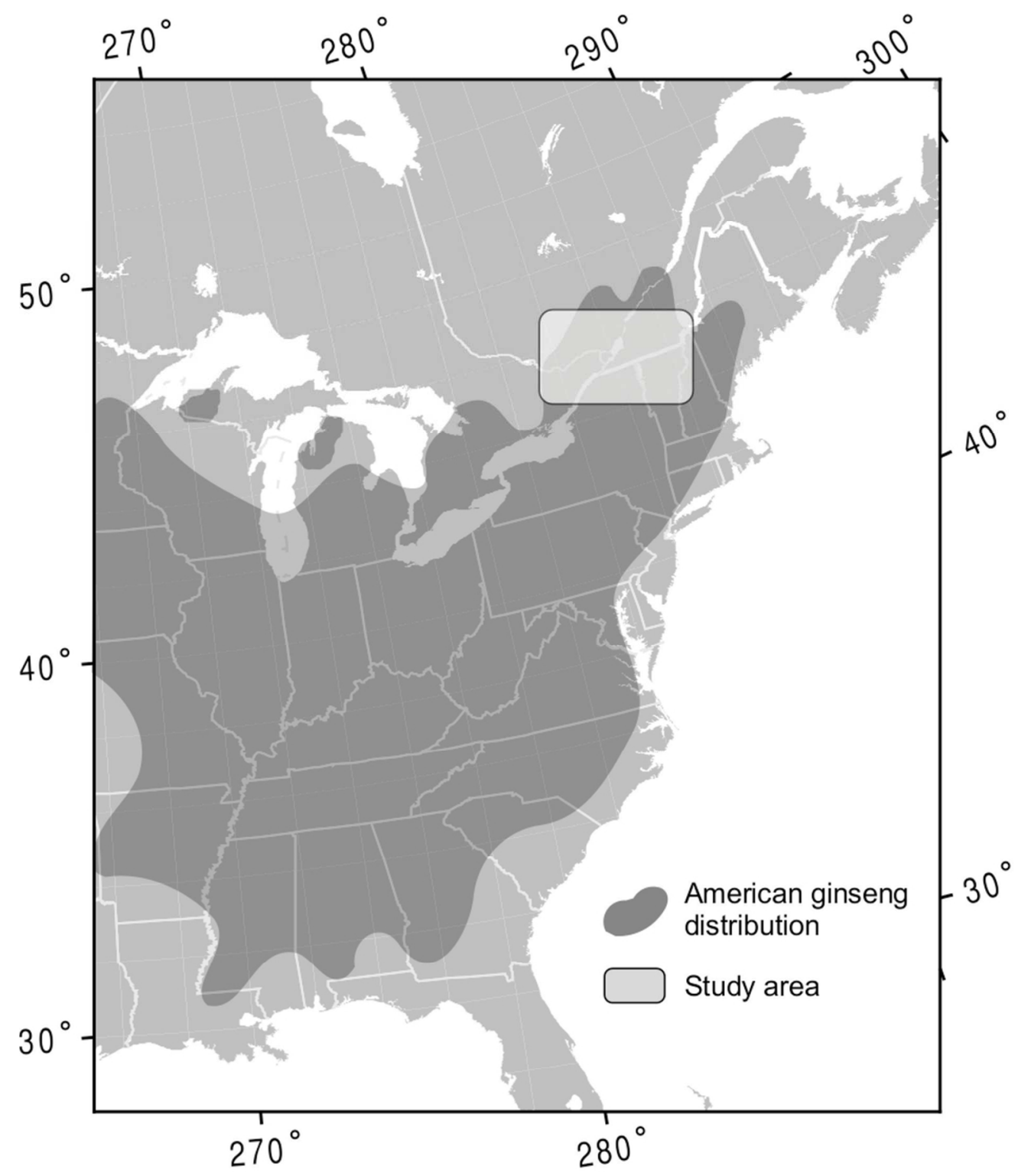

Figure 1. American ginseng (Panax quinquefolius) distribution (modified from Argus and White 1987) and study region from where the six populations were sampled.

Fig. 1

$93 \times 109 \mathrm{~mm}(300 \times 300$ DPI $)$ 
A) Nuclear genome

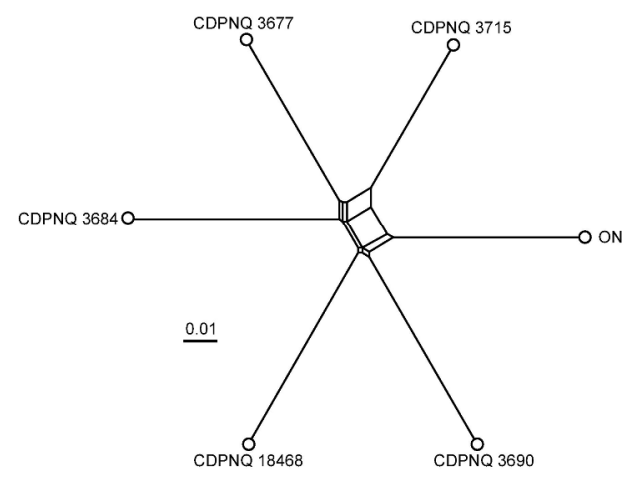

B) Chloroplast genome



C) Mitochondrial genome
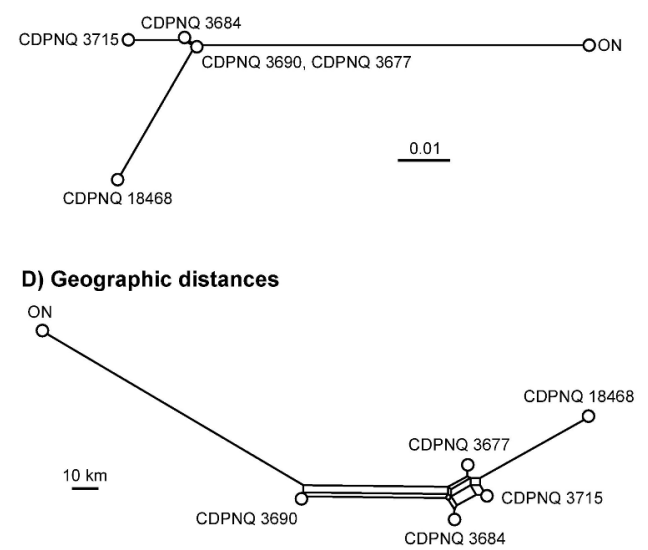

Figure 2. Networks representing the pairwise $F_{S T}$ distances between populations for $(A)$ the nuclear genome, (B) the chloroplast genome, and (C) the mitochondrial genome, as well as the pairwise geographic distances between populations (D). Boxes in the network indicate conflicting signal in the data. Bars indicate $F_{S T}$ distances $(A, B, C)$ or geographic distances in $\mathrm{km}(D)$.

Fig. 2

$196 \times 493 \mathrm{~mm}(300 \times 300$ DPI $)$ 